


\section{Sin fuentes no existe periodismo}

\section{Roque Rivas Zambrano*}

Fecha entrega: 2013-04-13 • Fecha aprobación: 2013-04-29

\section{Resumen}

Ryszard Kapuściński solía decir que "una característica del reportero debe ser la empatía, esa habilidad de sentirse inmediatamente como de la familia. Compartir dolores, sufrimientos y alegrías de la gente que, rápidamente, percibe si él está realmente 0 si es un extraño que viene, mira y se va". Esta frase resume la esencia de este oficio, donde el periodista está comprometido con las historias. En el presente artículo se detallan los aspectos de una de las herramientas más importante con la que cuenta un reportero: la fuente, que puede ser una persona, el mundo circundante o un documento. Sin este recurso no hay periodismo real.

\section{Palabras clave}

Periodismo. Fuentes. Medios. Comunicación. Reporteros. Géneros. Noticias. Crónicas

\section{Abstract}

Ryszard Kapuściński solía decir que "una característica del reportero debe ser la empatía, esa habilidad de sentirse inmediatamente como de la familia. Compartir dolores, sufrimientos y alegrías de la gente que, rápidamente, percibe si él está realmente 0 si es un extraño que viene, mira y se va". Esta frase resume la esencia de este oficio, donde el periodista está comprometido con las historias. En el presente artículo se detallan los aspectos de una de las herramientas más importante con la que cuenta un reportero: la fuente, que puede ser una persona, el mundo circundante o un documento. Sin este recurso no hay periodismo real.

\section{Keywords}

Periodismo. Fuentes. Medios. Comunicación. Reporteros. Géneros. Noticias. Crónicas

\footnotetext{
* Roque Rivas Zambrano, catedrático de la Facultad de Comunicación Social. Es Editor del diario La Hora. Ha hecho radio, comunicación institucional y consultoría. Tiene postgrado en Opinión y Periodismo en Argentina. Fue dirigente de organizaciones de periodistas. Recibió el premio nacional de Prensa (1997) entregado por la Unión Nacional de Periodistas y la condecoración al Mérito Laboral otorgado por el Ministerio de Trabajo.
} 


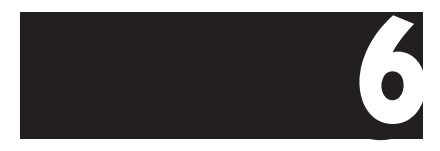

\section{.}

$\mathrm{U}$ $\mathrm{n}$ medio sin fuentes es un medio muerto". Así lo sentenció la docente, periodista y experta en comunicación española, María del Mar de Fontcuberta Balaguer. Según la catedrática, además de la observación directa de los hechos, los periodistas necesitan buscar otras fuentes. En mis clases de "Periodismo", les digo a los estudiantes que "el periodismo sin fuentes no existe", igual que los reporteros sin contactos. Los géneros periodísticos -noticia, entrevista, perfil, testimonio, crónica, reportaje, ensayo, relato y opinión- necesitan las fuentes. Los diarios impresos y digitales; los canales de televisión, las radios y las revistas - públicos o privados- requieren recoger las voces de las personas involucradas. Por lo tanto, como catedrático, creo en la importancia de compartir con los alumnos, mostrando ejemplos reales, el manejo de las fuentes en los medios de comunicación masiva y portales informativos alojados en Internet.

\section{Conceptos imprescindibles}

Ryszard Kapuscinski, periodista polaco y autor del libro "Los cínicos no sirven para este oficio", se pronunció repetidas veces sobre este gran recurso periodístico. Para él, existían tres tipos de fuentes: "la principal son los otros (y nosotros), la gente. La segunda son los documentos, los libros, los artículos

sobre el tema. La tercera es el mundo que nos rodea, en el que estamos inmersos: los colores, las temperaturas, atmósferas, el clima, todo eso que llamamos imponderabilidad, que es difícil de definir y que, sin embargo, es una parte esencial del escritura".

Cuando el escritor polaco apunta a la gente como fuente de información, hace referencia a las personas que viven en las ciudades del mundo. $\mathrm{Si}$ pensamos solo en Quito, donde viven dos millones de perso-

Los diarios mpresos y digitales; as radios y las revistas -públicos o privadosrequieren recoger las voces de las personas involucradas. nas, podemos concluir que tenemos el mismo número de fuentes y también de historias. En mi biblioteca, tengo otro libro, escrito por Sibila Camps y Luis Pazos. Se titula "Así se hace periodismo" e incluye una lista de fuentes que está encabezada por la "observación directa" del reportero para cumplir sus tareas. Cuando el reportero se encuentra en el lugar donde ocurre el hecho, las primeras informaciones provienen de lo que está viendo, sin perjuicio de que también sea necesario realizar entrevistas. Los elementos en los cuales tendrá que reparar dependerán del tipo de nota. Hay varias clasificaciones de fuentes de información. Esta división puede estar relacionada con el grado de proximidad con el hecho, el conocimiento sobre el acontecimiento, el compromiso con lo sucedido y sus actores o la confiabilidad de la fuente. La clasificación básica de la que hablan Camps y Pazos es la siguiente:

- La observación directa

- La gente
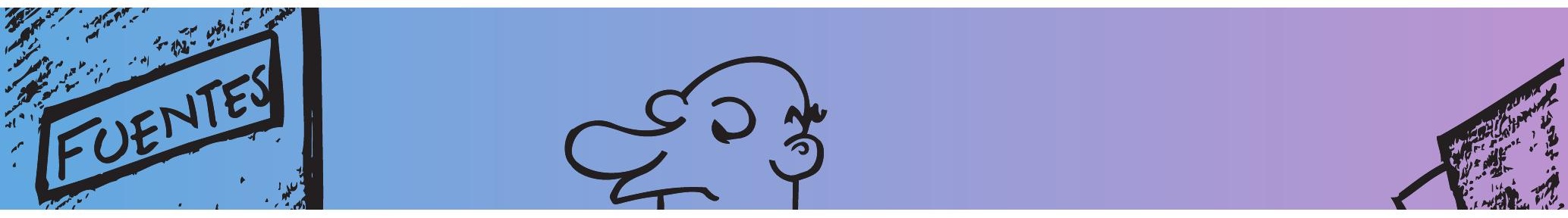
- Los protagonistas (víctimas, culpables, sospechosos, familiares, autoridades)

- Los voceros y jefes de prensa (de funcionarios, políticos, empresarios)

- Los contactos (personas a las que el periodista recurre con cierta asiduidad y con las que mantiene una relación de cierta confianza).

- Las agencias de prensa (equipos de periodistas o licenciados en comunicación que las instituciones o empresas contratan de forma permanente o por una actividad determinada).

- Los periodistas de otros medios (colegas de otras ciudades del país o de la misma ciudad, que son consultados sobre hechos que ocurren en sus áreas de influencia).

- Los documentos

- Cables

- Documentos propiamente dichos (con autoría y procedencia plenamente probada).

- Documentos no convencionales (materiales escritos -impresos o manuscritos- que en determinadas circunstancias cumplen el rol de fuentes).

- Archivos periodísticos

- Redes informáticas

- Estadísticas, encuestas y sondeos de opinión

- Material bibliográfico.

- Fotos

- Vídeos

- Discos, CD, cassetes, etc.

- Otros medios

- Diarios y revistas

- Radios

- Televisión

- $\quad$ Agencias de noticias

- Internet

- La parainformación

- Visitas y llamados a la redacción.

- Anónimos

- Rumores

- $\quad$ Chistes y apodos

- Campañas y avisos clasificados

- "Leer" la ciudad (afiches, volantes, pasacalles, pintadas, graffitis)

Este libro tiene un capítulo dedicado a las "fuentes información y las técnicas para obtenerlas". Cito también el libro "Cómo se fabrican las noticias. Fuentes, selección y planificación", de Manuel López, quien señala que "la fuente informativa es una persona, un grupo de personas, una institución, una empresa, un gobierno, una religión, una secta, un club deportivo... y quién sabe cuántas variables más, que han visto u oído algo, o que tienen documentos sobre ese algo y que están dispuestos a proporcionarlo a un medio informativo por interés público o porque conviene a sus propias estrategias".

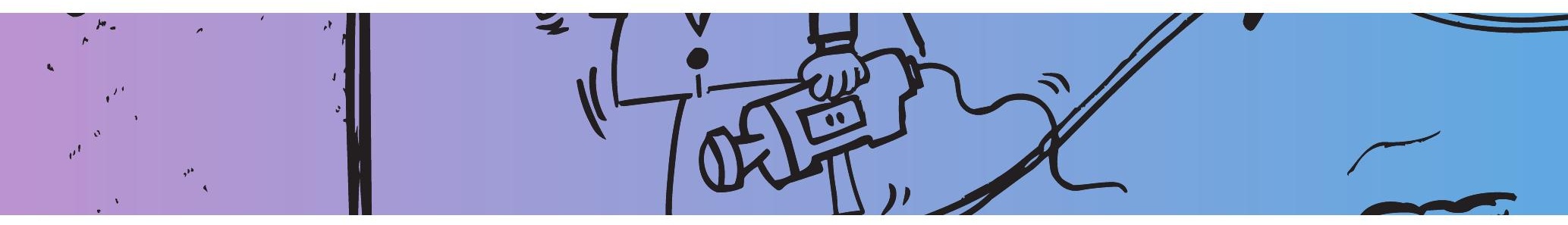


Además, el británico David Randall, en su obra "El periodista universal” (1999), ofrece un conjunto heterogéneo de recursos que, sin intención de constituirse en una posible clasificación de fuentes, resulta orientador al momento de definir posibles ámbitos donde el periodista puede obtener informaciones de valor. Entre las opciones menciona la observación, la gente, los contactos permanentes, los políticos, los informes oficiales, los grupos de presión (entidades privadas, ONG, entre otras), las organizaciones internacionales, las universidades y centros de investigación, las publicaciones académicas, la prensa alternativa, las revistas especializadas, la policía y los servicios de urgencia, los libros y guías, los otros medios de comunicación e, incluso, las efemérides y los avisos clasificados.

\section{Los contactos}

José Ignacio Armentia Vizuete y José María Caminos Marcet, docentes e investigadores de la Universidad del País Vasco, España, en su libro "Fundamentos de Periodismo Impreso" (2003), señalan que la relación entre el medio de comunicación y las fuentes de información determina uno de los aspectos más relevantes del trabajo periodístico. "Las fuentes lo impregnan todo, y su importancia es tan grande que el trabajo con unas u otras fuentes aporta claras pistas sobre la estrategia informativa de los medios de comunicación (...) El mejor medio es el que tiene acceso a la información diferenciada; es decir, el que trabaja con las mejores fuentes". En su proceso de producción periodística, los medios van construyendo una red de fuentes informativas que se va reconfigurando, de manera permanente, a partir de su selección y jerarquización cotidiana.

\section{Factores determinantes}

El contacto con las fuentes depende de algunas variables:

- Del interés del periodista, cuya agenda y relaciones se renuevan en el proceso de inclusión, exclusión y jerarquización de fuentes.

- Del interés de la fuente, cuya relación con el periodista y con el medio no es de carácter lineal y está marcada por el mutuo interés y por el riesgo del conflicto.

- Del medio de comunicación, cuya línea editorial, prestigio y credibilidad pueden lograr el acceso a determinadas fuentes o el alejamiento de otras.

- Del proceso productivo, a partir del cual los medios tienden a trabajar preferentemente con aquellas fuentes que les brindan materiales noticiosos ya acabados y que no precisan de la reelaboración del periodista.

\section{Fuentes oficiales}

Según el Proyecto Antonio Nariño, publicado en Bogotá, cuando se trata de fuentes oficiales, se pueden presentar las siguientes situaciones:

- Ocultamiento de la información: tratar de esconder o limitar ciertos datos, encubrir situaciones o actos comprometedores.

- Filtración de información: usar indebidamente al periodista para dar una información.

- Jerarquización: privilegiar a los medios más poderosos para entregar la información, lo cual afecta de manera significativa a medios locales e independientes.

- Manipulación de la información: cambiar una chiva por un cubrimiento positivo o por callar lo negativo de un hecho, manejar la información con el esque- 
ma premio/castigo o como una prebenda para ejercer control, usar privilegios para incentivar la difusión de una información -viajes, fiestas, comidas y más-.

- Falta de claridad en el flujo de la información: no saber a ciencia cierta quién la da o cómo obtener la información.

- Pedir, mediante la exigencia de ser parte de su causa: pedir apoyo incondicional y lealtad.

- Pedir favores a los periodistas: servir de informantes o hacer inteligencia

- Pedir a los periodistas que incluyan información que sólo beneficia a la fuente y es irrelevante para el lector.

- Censura: recibir presión para dejar de publicar alguna información

- Intimidación: amenazar por publicar ciertas notas o denuncias

Una de las anécdotas periodísticas, que grafica el punto de ocultamiento de información, se encuentra en el libro "Antídoto contra el silencio". La historia de Mónica Almeida se titula: "Una historia de método, constancia y pasión”. Ella era reportera de Diario Hoy (hace más de 20 años), cuando publicó su primer trabajo de periodismo de investigación. El Gobierno social-demócrata, de Rodrigo Borja (1988-1992), había entregado, al entonces diputado Fabián Alarcón, asignaciones extraordinarias de dinero, que superaban con creces la cantidad fijada por la ley, para que realizara obras en Pichincha.

Algunos de los supuestos beneficiarios de las asignaciones, como ciertas escuelas, no sabían que lo eran. Estos montos se comprometieron porque el voto del legislador era clave para cambiar la mayoría del Congreso y quitarle la presidencia al cefepista Averroes Bucaram, ganada en 1990, con el apoyo de los roldosistas y socialcristianos. En esa ocasión, Alarcón se negaba a conceder una entrevista a la periodista. Solo bajo una amenaza de publicar el reportaje, sin su versión, el legislador decidió dar declaraciones al respecto.

\section{Otras categorizaciones de las fuentes}

Para los investigadores españoles Armentia Vizuete y Caminos Marcet, en su libro "Información: redacción y estructura" (1998), las fuentes tienen otras variables según las cuales se pueden clasificar. Entre las más importantes, anotan:

- Según la duración de la relación, en estables y provisionales

- Según la posición desde la que actúan, en públicas, privadas, confidenciales y expertas.

- Según la actitud respecto al periodista, en activas y pasivas

- Según la representatividad, en gubernamentales y no gubernamentales

- Según el alcance de la información que suministran, en centrales y territoriales

La española Isabel Villaseñor Rodríguez, en su libro "Las fuentes de información: estudios teórico-prácticos" (1999), complementa la tarea de la investigación con un plan de búsqueda de información, que está más apegado al campo de la biblioteconomía y la documentación y que puede resultar útil en la búsqueda de datos. Considera, además, la distinción que, en los tipos de fuentes, introduce su procedencia $u$ origen -punto en el que coincide con las clasificaciones de tinte periodístico-. Para esta autora, también es necesario suponer otros criterios:

- Por la procedencia y origen de la información: en personales, institucionales y documentales.

- Por el canal utilizado: de transmisión oral y de transmisión documental.

- Por la cobertura geográfica: de carácter internacional, nacional, autonómico, regional y local.

- Por el grado de adecuación de la información que ofrecen: total, media e insuficiente.

- Por el tipo de información que presentan: especializada y general 
El Clarín, en su "Manual de Estilo" (1997), añade que "la mejor fuente para el desarrollo de una información y para el lector es la que se identifica con nombre y apellido". Sin embargo, para conseguirla y conservarla es necesario tener en cuenta varias consideraciones.

\section{Las experiencias}

Steve Buttry, un editor de transformación digital para medios, es un periodista que ha pasado más de 40 años en el negocio de las noticias. Empezó su formación en el oficio en la década de 1990 y, en el 2005, la convirtió en una actividad de tiempo completo, cuando fue a trabajar en el American Press Institute. Pasó tres años en la enseñanza e investigación de la innovación y la formación de periodistas y ejecutivos de periódicos de todo el mundo. Este profesor adjunto de Georgetown desarrolló un "Manual para cultivar y desarrollar las fuentes". En él, se detallan los aspectos más importantes sobe este tema fundamental para el ejercicio profesional. Por lo tanto, lo transcribiré a continuación, con el único afán de que estos consejos sean de ayuda para los estudiantes que piensan dedicar su vida "al mejor oficio del mundo", como denominó el escritor colombiano Gabriel García Márquez al periodismo.

\section{Manual para cultivar y desarrollar las fuentes}

\section{Encontrando las fuentes}

Busque nuevas fuentes. Intente cultivar nuevas fuentes más allá de las personas que consulta regularmente en su área de cobertura. Si siempre habla con hombres blancos, intente hablar con mujeres de grupos minoritarios, quienes, posiblemente, le darán otro punto de vista sobre la misma cuestión y podrán generar en usted nuevas ideas. Si siempre habla con jefes y profesionales, intente hablar también con los empleados y los obreros.

Si siempre habla con los liberales, también hable con los conservadores. Si siempre habla con personas de su edad, intente establecer contacto con personas mayores o menores que usted. Estas personas, con diferentes perspectivas, lo guiarán hacia otras historias. Trate de advertir quién es el funcionario de mayor perfil de la agencia u organismo que usted cubre regularmente. Dedique el tiempo necesario para ver si obtiene datos que lo lleven hacia diferentes versiones. Pregúntese periódicamente si ha podido establecer un contacto significativo con una nueva fuente. Si no fue así, pregúntese si lo podría haber hecho.

Hable con los clientes. Si está asignado a cubrir un organismo gubernamental o una entidad comercial, asegúrese de que el conjunto de fuentes trascienda las fuentes oficiales de tal organización. Hable con aquellos ciudadanos que acuden a tal organismo o negocio y hacen uso de sus productos o servicios.

Si algunos de estos usuarios o clientes están organizados, debería tener un contacto periódico con los líderes de dichas organizaciones. Puede ser que también deba tratar con aquellos individuos que se autodenominan defensores de los consumidores y con los consumidores molestos. Establezca un punto para interactuar con algunos consumidores promedio, que no pertenezcan a ninguna organización.

Investigación. Tómese tiempo para buscar posibles fuentes e historias. Realice un determinado viaje o fije una entrevista sin tener una idea en especial. Visite a una 
fuente que no ve desde hace un tiempo o a una comunidad o agencia sobre las cuales no ha informado. Trate de familiarizarse nuevamente con sus fuentes, dedíquele el tiempo necesario para ponerse al día sobre los acontecimientos que han ocurrido desde la última vez que las vio. Es probable que, luego de estos reencuentros, puedan surgir nuevas ideas para escribir historias. Quizás no obtenga las pautas para escribir sobre un tema en particular, pero es posible que, por lo menos, obtenga datos relevantes que puedan ser utilizados para perseguir otros proyectos.

Además, de estas visitas puede resultar una nueva fuente a quien contactar en el futuro. Por lo menos, de esta manera tendrá mayor comprensión sobre lo que ocurre en su comunidad y en las organizaciones que se encuentran dentro del área que usted cubre.

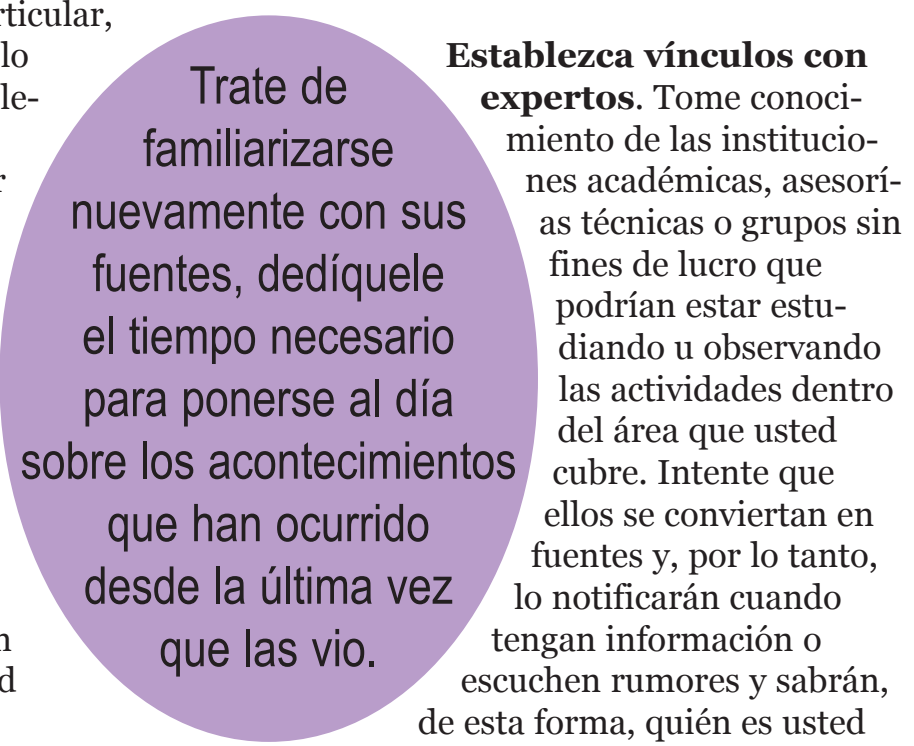

Cuando uno explora e investiga, siempre surgen nuevas historias y es productivo el tiempo que se invierte haciendo esto. Sencillamente, no le anticipe al editor sobre lo que usted va a escribir.

\section{Aprenda a buscar registros y} documentación. Tome conocimiento de los documentos y archivos electrónicos de las organizaciones que suele cubrir. Intente aprender sobre aquellos documentos a los cuales se puede acceder públicamente, sobre los que son legalmente confidenciales y los que pueden llegar a presentar conflictos en torno a su acceso. Pida dicha documentación con frecuencia, independientemente de que la vaya a usar o no. Esto les permite a las fuentes saber cuáles son sus intereses. La búsqueda de ciertos registros en las historias de rutina establece un precedente cuando usted busca registros similares para escribir artículos de otras magnitudes. Siempre que sea posible, solicite tales registros en formato electrónico. Sepa quiénes son los individuos que pueden acceder a la información confidencial (no solamente dentro de la organización sino también clientes o usuarios que pueden llegar a obtenerla). Sepa qué información está disponible en la Internet (entonces, puede acceder a la misma de noche, durante los fines de semana y no debe pedírsela a nadie).
Trate de miento de las instituciones académicas, asesorías técnicas o grupos sin fines de lucro que podrían estar estudiando u observando las actividades dentro del área que usted cubre. Intente que ellos se conviertan en fuentes y, por lo tanto, lo notificarán cuando scuchen rumores y sabrán, de esta forma, quién es usted cuando intente contactarlos para obtener el análisis sobre algún tema o hecho en particular. Las tendencias que se esbozan en las investigaciones realizadas por los expertos no son improductivas, pero usted debe también percibirlas y conocerlas.

\section{Desarrolle lazos con fuentes}

nacionales. Entable contacto con asociaciones nacionales, expertos académicos y organismos del gobierno para contar con fuentes especializadas dentro de las áreas que usted cubre. Puede que lo asistan con material valioso para una historia local, o pueden tener conocimientos de lo que está ocurriendo dentro de ese ámbito. Puede que le comuniquen cuando se esté registrando una tendencia de carácter nacional.

\section{Relaciones con las fuentes}

Disponibilidad. Permita que las personas en su área de cobertura sepan 


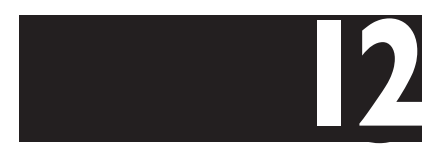

que usted está interesado en recibir información, sugerencias, quejas y más. Asegúrese de darles su número de teléfono y dirección de correo electrónico. Si le parece apropiado, deles también su número de teléfono celular. Contáctese con ellos periódicamente, a través del teléfono y personalmente.

Sea honesto. Nunca engañe a una fuente. Sea honesto con respecto a la dirección que está tomando una historia. Si se trata de algo negativo, no lo rotule de otra manera. Si no va a hacer referencia a alguno de los datos ofrecidos por una fuente, no les diga que va utilizar dicha información. Esto significa que no tiene por qué inquietar a sus fuentes innecesariamente. Si una fuente está preocupada en cuanto a una historia negativa, asegúrele que usted escribirá la historia de forma parcial y precisa y que está interesado en escuchar su versión.

Sea insistente en cuanto a la precisión. Si alguien le ofrece datos de memoria, pregúntele dónde encontró tal información y, posteriormente, verifique la fuente original. Llame nuevamente a las fuentes, para cerciorarse de la exactitud de las cifras, ortografía, cronologías y más. Solicite reportes, documentos o directorios personales, calendarios que pueden confirmar la ortografía, números y otros datos. Esto no sólo contribuye a incrementar la exactitud en sus historias, sino que también ayuda a ganarse la confianza de las fuentes (y la buena voluntad que usted necesitará si llega a cometer algún error). Esto les indica a las fuentes que usted pretende obtener la información exacta sobre cada hecho o acontecimiento.

Conviértase en un experto. Cuanto más usted aprenda sobre temas complejos, tecnológicos y económicos, mayor será el respeto que sus fuentes tendrán por usted, más difícil será engañarlo, y a usted le resultará más fácil vislumbrar el potencial de determinadas historias. Lea libros, artículos, reportes. Navegue por la Internet. Haga muchas preguntas.

Reconozca que usted no es un experto. Si no sabe o no entiende algo, pregunte. Las fuentes respetarán su honestidad y, de este modo, usted estará aprendiendo. También corre el peligro de ser descubierto y perder credibilidad en caso de que esté simulando estar comprendiendo algo en particular. Repítale a la fuente lo que interpretó para cerciorarse de haber comprendido correctamente.

Demuestre interés. Es posible que las fuentes quieran que usted escuche algo que no es precisamente lo que tenía en mente. Puede ser que, igualmente, obtenga datos interesantes. Aunque la fuente piense que el dato que le está brindando puede ameritar la redacción de un artículo y usted no está de acuerdo, igualmente demuestre su interés. Por más aburridora o molesta que pueda llegar a ser una de sus fuentes, por más insustancial que crea que es el dato que le están proporcionando, usted nunca sabe cuándo necesitará obtener alguna información. Aunque los datos provistos sean totalmente insignificantes, la fuente valorará su interés y puede que algún día le comente un apunte relevante o interesante.

Coménteles sus intereses a las fuentes. Coménteles, a sus fuentes, sobre las historias que está escribiendo, incluso si las mismas no se relacionan directamente con ellas. Si bien puede saber perfectamente que una fuente no tiene vínculos con el tema en el cual usted está trabajando, se puede dar que dicha fuente lo guíe hacia otras fuentes potenciales, o pueda llegar a transmitirle algún dato interesante que escuchó en la oficina.

Considere a las fuentes como si fuesen personajes. Es verdad que usted no va a crear el perfil de todos los individuos que trabajan en su área de cobertura, 
pero puede ser que, algún día, llegue a elaborar el perfil de alguno de ellos. Por lo tanto, intente concebir a las fuentes como si fuesen personajes a quienes debe explorar en profundidad. Aprenda sobre sus familias, pasatiempos, historias de vida, cuadros de deportes favoritos, lugares que suelen frecuentar. Percátese de sus gestos. Aunque nunca elabore un perfil sobre tal persona, al aprender estas cosas logra que, eventualmente, la misma pueda proporcionarle un dato interesante que escuchó a través de algún miembro del grupo social al cual pertenece.

Establezca conexión. No tenga miedo de mostrar su lado humano. Si sus hijos tienen la misma edad que los de la fuente, converse sobre los asientos para bebés, sobre las cadenas de auto para llevar a los niños a la escuela, o sobre el seguro de los autos, cualquier tema acorde con la edad de los niños. Si la fuente odia a su equipo favorito de fútbol, converse sobre otro tema de carácter trivial. Si algún familiar de la fuente está enfermo, demuestre su genuina compasión. No simule mimetizarse con la persona ni tampoco fuerce algo que no fluya naturalmente, por el contrario, intente generar una apertura sincera para establecer una conexión. Si tiene algo en común con la persona, intente conectarse con ella mediante un interés verdadero y, por un momento, deje a un lado el aspecto profesional.

Comparta control. Aunque una fuente pase mucho tiempo con los reporteros, probablemente, no se sienta del todo cómoda frente a ellos y sus libretas de apuntes. Intente brindarle, ocasionalmente, cierto control durante la entrevista.

Evidentemente, usted es el que está entrevistando, pero si le llegan a realizar alguna pregunta, intente contestarla. Escuche con cortesía cuando la persona se desvíe, eventualmente, del tema en cuestión.

Tome control. Haga sus preguntas directamente. Si la persona evade alguna, formúlela nuevamente. Sin importar cuáles sean los detalles que invitan a establecer un vínculo con la fuente, usted debe hacerle saber que su interés en la relación está basado en la comprensión y recepción de información.

Mantenga registro de sus fuentes. Utilice programas informáticos como Outlook u hojas de cálculo, para mantener un registro de sus fuentes. Consiga los números de la oficina, casa, celular, de sus refugios de descanso como también las direcciones de correo electrónico. Mantenga registro del nombre de sus secretarias, hijos, cónyuge, de la localidad donde viven, antiguos trabajos, universidades donde concurrió, todo lo que pueda resultarle útil en un futuro.

Solicite documentación. Siempre solicite documentos sobre lo que le dicen las fuentes. No debe hacerlo con una actitud desafiante. Plantéelo como parte de su rutina para obtener la máxima precisión. Si la fuente se muestra reacia a hablar oficialmente de un tema en particular, dígale que puede atribuir tal información a un documento en lugar de atribuírsela a ella. Los documentos representan la posibilidad de verificar la información. Pueden, incluso, arrojar detalles que la fuente desconocía o de los cuales no se acordaba, y también pueden dirigirlo hacia otras fuentes. Asimismo, establecen un precedente. Si una fuente le da un documento cuando tiene algún interés personal en determinado asunto, le resultará difícil, posteriormente, afirmar que esa clase de documentación es clasificada.

\section{Identificando y evitando los problemas}

Información oficial. Siempre que sea posible, mantenga sus conversaciones dentro del plano oficial, especialmente, si está tratando temas que son bien manejados por sus fuentes. Las fuentes deben entender, en todo momento, que la relación que 
usted tiene con ellas es profesional y que su trabajo consiste en recabar y obtener información. Cuando deba tratar un tema de forma extra oficial, asegúrese de que sea por motivos justificados. Por ejemplo, si una fuente le comenta algo que no sabe de primera mano, no debería citarla, pero el dato lo puede conducir hacia otras fuentes que conozcan el tema con mayor profundidad. Si conversa con la fuente extraoficialmente, asegúrese de que ambos entiendan las condiciones de la conversación: ¿Se puede publicar la información, pero no mencionar a la fuente? Si es así, intente llegar a un acuerdo para poder brindarle al lector la descripción de la fuente de la forma más precisa posible. ¿̇Se puede publicar la información manejada en la conversación? Si es así, hágale saber a la fuente que usted intentará publicar dicha información usando otras fuentes. Antes de entrar en el plano extra oficial, dígale a la fuente que intentará oficializar algo de lo mencionado si llega a decir algo que usted quiere usar. Si lo hace, vuelva después con la información o comentarios que quiere usar e intente oficializar la información.

Hágale frente a la música. Cuando escriba una historia que puede llegar a enfadar a alguien, pase por su oficina el día de publicación de la nota, o llame, sea para preguntar por la historia, para hacer un seguimiento o utilice cualquier otro pretexto. Dele a la persona una oportunidad para que hable. Si ha cometido algún error, reconózcalo. $\mathrm{Si}$ no lo ha hecho, mantenga su posición, pero sea respetuoso. Muchas fuentes (políticos, abogados, directores técnicos, deportistas) están acostumbradas a mantener relaciones respetuosas con sus adversarios y serán respetuosos con usted, y seguirán brindándole información, si demuestra respeto y el coraje suficiente para hacerle frente a la situación cuando haya escrito algo molesto para ellos. Este también es un buen momento para conseguir nuevas informaciones. Si alguien se muestra molesto por una historia negativa, pregúntele qué cosas buenas están ocurriendo den- tro de su jurisdicción. Si le comenta que las cosas malas en su oficina no son tan desastrosas como las que están pasando en la oficina de al lado, pídale que sea más específico al respecto. Nunca evite a alguien que está enfadado con usted (o a alguien con el cual usted está enfadado). Hágales saber, por medio de sus palabras y acciones, que deben tratar con usted y que su comportamiento será absolutamente profesional.

Reconozca sus errores. Si comete un error (o si el diario comete un error relacionado con su área editorial), reconozca dicho error, corríjalo y discúlpese personalmente con aquellos que resultaron afectados. La gente entiende que errar es humano y respetan a quienes asumen la responsabilidad en tales circunstancias. Si no se trata de un error, o si no se puede determinar con claridad si usted se ha equivocado (como el disenso sobre cierta afirmación, en lugar de un dato factual), escuche atentamente el reclamo que expresa su interlocutor. Aunque no esté de acuerdo, exprese su opinión y dígale a la fuente por qué escribió la historia de tal manera. Considere si es necesario escribir una historia para seguir de cerca el tema en cuestión. Si esto no se justifica, sugiérale escribir una carta al editor $u$ ofrézcale un derecho a réplica. Ponga a su editor al tanto de la situación y comuníquele cómo ha manejado la situación. Si la fuente llega a dirigirse al editor para presentar su reclamo, usted estará contento de haberle comentado previamente la situación.

Evite acercarse demasiado. Si su relación con una fuente pasa de ser amigable a convertirse en una amistad, es posible que deba replantear la relación. Quizás, deba hacerle algunas preguntas difíciles para recordarle la naturaleza de su profesión. No debería, ni puede, aislarse de la vida comunitaria, pero si se encuentra frecuentemente con las fuentes en la Iglesia o en los partidos de fútbol de los niños o en otros eventos de estas características, es probable que deba establecer algu- 
nos límites. Si percibe que una de las relaciones que mantiene se está tornando demasiado íntima, convérselo con su editor. Tal vez, también deba conversarlo con la fuente en cuestión. Puede ser que la fuente se sienta un poco incómoda, pero, posiblemente, aprecie el hecho de que podrán juntos alentar a sus respectivos hijos en un partido de básquetbol y, al otro día, conversar profesionalmente sobre la cobertura de noticias o sobre un documento en particular.

\section{Establezca vínculos con sus colegas}

Determine si otros reporteros, dentro de su área de cobertura, conforman alguna asociación periodística o participan de algún foro profesional. Puede aprender técnicas, desarrollar ideas y establecer nuevas fuentes por medio de sus colegas. Si no participa de ninguna asociación o foro de discusión, lea otros diarios en Internet que sean de comunidades similares a la suya. Puede contactarse por teléfono o vía electrónica con otros reporteros para tratar los mismos temas.

- Las fuentes y el periodista cooperan. Fuente y periodista tienen algunos objetivos comunes: uno necesita que una determinada información se publique, y otro necesita obtener noticias para satisfacer a sus superiores o para vender más periódicos. En determinadas ocasiones, las fuentes filtran una información que les interesa que aparezca y que los medios no se pueden resistir a publicar.

- La fuente es la que, prácticamente, hace la noticia. Sería el caso de los comunicados oficiales. A partir de la proliferación de los gabinetes de prensa, aumenta la denominada "información convocada", en la que la fuente hace la noticia.

\section{Fuentes consultadas}

- Armentia Vizuete, José Ignacio; Caminos Marcet, José María, La información: Redacción y Estructuras. Servicio Editorial de la Universidad del País Vasco. Bilbao, 1998.

- $\quad$ Armentia Vizuete, José Ignacio; Caminos Marcet, José María, Fundamentos de Periodismo Impreso. Editorial Ariel. España, 2003.

- Buttry, Steve, Cultivando y desarrollando fuentes. Artículo publicado en la página de Ijnet (Red de periodistas internacionales).

- Camps, Sibila; Pazos, Luis, Así se hace periodismo. Manual práctico de periodismo moderno. Beas Ediciones, Buenos Aires, 1994.

- $\quad$ Fontcuberta, Mar; Borrat, Héctor, Periódicos: sistemas complejos, narradores en interacción. Ediciones La Crujía. Buenos Aires, 2006.

- Fontcuberta, Mar. La noticia. Pistas para percibir el mundo, Paidós, Buenos Aires, 1993.

- Kapuscinski, Ryszard. Los cínicos no sirven para este oficio. Editorial Anagrama, Barcelona, España, 2002.

- López, Manuel, Cómo se fabrican las noticias. Fuentes, selección y planificación. Editorial Paidós. Papeles de Comunicación 9. España, 1995.

- Proyecto Antonio Nariño. El papel de las fuentes oficiales en la calidad del periodismo colombiano. Bogotá, 2004.

- $\quad$ Randall, David, El periodista universal. Editorial Siglo XXI. España, 1999.

- Recopilación, Antídoto contra el silencio. Fundamedios. Ecuador, 2012.

- Ruiz, Adela. Memorias de las XI Jornadas nacionales de investigación en Cominacación, Mendoza, Argentina, 2007.

- Villaseñor, Isabel, Las fuentes de información: estudios teórico-prácticos. Editorial Síntesis. Madrid, 1999. 